Article

\title{
Selective and Mutual Separation of Palladium (II), Platinum (IV), and Rhodium (III) Using Aliphatic Primary Amines
}

\author{
Kazuya Matsumoto*(D), Yuto Sezaki, Sumito Yamakawa, Yuki Hata and Mitsutoshi Jikei \\ Department of Materials Science, Graduate School of Engineering Science, Akita University, 1-1 \\ Tegatagakuen-machi, Akita-shi, Akita 010-8502, Japan; sezaki.y@yahoo.ne.jp (Y.S.); smi.kun.12@gmail.com (S.Y.); \\ wimper_h_1114@outlook.jp (Y.H.); mjikei@gipc.akita-u.ac.jp (M.J.) \\ * Correspondence: kmatsu@gipc.akita-u.ac.jp; Tel.: +81-18-889-2745
}

Received: 16 February 2020; Accepted: 28 February 2020; Published: 29 February 2020

check for updates

\begin{abstract}
The selective recovery of platinum-group metals (PGMs) remains a huge challenge. Although solvent extraction processes are generally used for PGM separation, the use of organic solvents is problematic because of their toxicity and environmental concerns. Here, we have developed a new PGM recovery method by precipitation from hydrochloric acid $(\mathrm{HCl})$ solutions containing $\mathrm{Pd}(\mathrm{II}), \mathrm{Pt}(\mathrm{IV})$, and $\mathrm{Rh}(\mathrm{III})$ using aliphatic primary amines as precipitants. $\mathrm{Pt}(\mathrm{IV})$ was precipitated using the amines with alkyl chains longer than hexyl independent of $\mathrm{HCl}$ concentration. The precipitation of $\mathrm{Pd}$ (II) required longer alkyl amines than octyl, regardless of the $\mathrm{HCl}$ concentration. $\mathrm{Rh}$ (III) was recovered by precipitation at high $\mathrm{HCl}$ concentrations using the amines longer than hexyl. The mutual separation of $\mathrm{Pt}(\mathrm{IV}), \mathrm{Rh}(\mathrm{III})$, and $\mathrm{Pd}(\mathrm{II})$, in this order, was successfully achieved by changing the $\mathrm{HCl}$ concentrations and alkyl chain lengths of the amines. X-ray photoelectron spectroscopy and thermogravimetric analysis evidently showed that the metal-containing precipitates were ion-pair complexes composed of metal chloro-complex anions and ammonium cations.
\end{abstract}

Keywords: platinum-group metal; metal precipitation; ion-pair; aliphatic primary amine; hydrochloric acid

\section{Introduction}

Platinum-group metals (PGMs), particularly $\mathrm{Pd}, \mathrm{Pt}$, and $\mathrm{Rh}$, are of crucial importance because of their wide range of applications, such as automobile catalysts and electrical devices [1-5]. Despite the increasing demand for PGMs, their availability remains limited due to their scarcity in Nature and regional maldistribution. Therefore, efficient recovery and separation processes are necessary to recycle PGMs from post-consumer scrap. Typically, solvent extraction is regarded as a practical method to recover and separate PGM ions from metal-containing aqueous solutions. For example, tertiary amines [6,7], organophosphates [8-11], and organosulfides [12,13] have been reported to act as $\mathrm{Pd}(\mathrm{II})$ or Pt(IV) extractants. However, solvent extraction processes require organic solvents, which are used as diluents of extractants or extractants themselves, and the use of organic solvents is problematic because of their toxicity and environmental concern. Furthermore, the selective recovery of PGMs remains a massive challenge due to the similarity in their properties.

The recovery mechanisms of PGMs by solvent extraction are generally classified into two types, namely, ligand-metal coordination and ion-pair formation [14]. For the coordination mechanism, metal extraction generally occurs in the order of $\mathrm{Pd}(\mathrm{II})>>\mathrm{Rh}(\mathrm{III})>>\mathrm{Pt}(\mathrm{IV})$; and $\mathrm{Rh}(\mathrm{III})$ and $\mathrm{Pt}(\mathrm{IV})$ are regarded as kinetically inert [15]. Furthermore, the order of extractability via ion-pair formation for the PGM chloro-complexes formed in an aqueous hydrochloric acid $(\mathrm{HCl})$ solution is reported to 
be $\left[\mathrm{MCl}_{4}\right]^{2-} \cong\left[\mathrm{MCl}_{6}\right]^{2-}>\left[\mathrm{MCl}_{6}\right]^{3-}>$ aqua species [16]; while the chloro-complex anions of PGMs formed in $\mathrm{HCl}$ are reported to be $\left[\mathrm{PdCl}_{4}\right]^{2-},\left[\mathrm{PtCl}_{6}\right]^{2-}$, and $\left[\mathrm{RhCl}_{6}\right]^{3-}$, as well as the chloro-aqua complexes of $\mathrm{Rh}(\mathrm{III})\left(\left[\mathrm{RhCl}_{4}\left(\mathrm{H}_{2} \mathrm{O}\right)_{2}\right]^{-}\right.$and $\left.\left[\mathrm{RhCl}_{5}\left(\mathrm{H}_{2} \mathrm{O}\right)\right]^{2-}\right)$ [14]. Therefore, the extractability of PGMs in ligand-metal coordination and ion-pair formation evidently indicates the difficulty in the selective recovery of $\mathrm{Pt}(\mathrm{IV})$ in priority to $\mathrm{Pd}(\mathrm{II})$ as well as the $\mathrm{Rh}(\mathrm{III})$ recovery in advance of $\mathrm{Pd}(\mathrm{II})$ and $\mathrm{Pt}(\mathrm{IV})$ by conventional solvent extractions.

Recently, we developed PGM recovery methods based on precipitation using aromatic primary amines as precipitants [17-20]. The selective precipitation of $\mathrm{Pt}(\mathrm{IV})$ from $\mathrm{HCl}$ solutions containing $\mathrm{Pd}(\mathrm{II})$ and $\mathrm{Pt}(\mathrm{IV})$ was successfully achieved using 4-hexyloxyaniline at high $\mathrm{HCl}$ concentrations [17]. Furthermore, the preferential and selective $\mathrm{Rh}(\mathrm{III})$ recovery from the mixture of $\mathrm{Pd}(\mathrm{II}), \mathrm{Pt}(\mathrm{IV})$, and $\mathrm{Rh}(\mathrm{III})$ in $\mathrm{HCl}$ was successfully accomplished using aromatic primary monoamines [18] or diamines $[19,20]$ as precipitants. The successful precipitation of $\mathrm{Rh}(\mathrm{III})$ was achieved based on the formation of unique ion-pair complexes comprising $\left[\mathrm{RhCl}_{6}\right]^{3-}$ and anilinium cations of the amines. Although the potential of aromatic primary amines for PGM precipitants has been revealed, studies on the capability of aliphatic primary amines for PGM precipitants, as well as PGM extractants have been limited. Therefore, investigations of the availability of aliphatic primary amines for PGM recycling are valuable in the viewpoint of recycling industry.

Herein, we present a new PGM separation method by precipitation from the mixed solution of $\mathrm{Pd}(\mathrm{II}), \mathrm{Pt}(\mathrm{IV})$, and $\mathrm{Rh}(\mathrm{III})$ in $\mathrm{HCl}$ using aliphatic primary amines as precipitants. Preferential and selective precipitation of $\mathrm{Pt}(\mathrm{IV})$ at low $\mathrm{HCl}$ concentrations was achieved using $n$-heptylamine and $n$-octylamine. Moreover, $\mathrm{Rh}(\mathrm{III})$ was recovered by precipitation in preference to $\mathrm{Pd}(\mathrm{II})$ at high $\mathrm{HCl}$ concentrations using $n$-heptylamine and $n$-octylamine. Thereafter, we successfully achieved the mutual separation of $\mathrm{Pt}(\mathrm{IV}), \mathrm{Rh}(\mathrm{III})$, and $\mathrm{Pd}(\mathrm{II})$ in this order by changing the $\mathrm{HCl}$ concentrations and the alkyl chain lengths of the amines. The mechanism of the selective precipitation of PGMs was studied by the analysis of the metal-containing precipitates.

\section{Materials and Methods}

\subsection{Materials}

$n$-Hexylamine, $n$-heptylamine, $n$-octylamine, $n$-nonylamine, $n$-decylamine, and $n$-dodecylamine were purchased from Tokyo Kasei Kogyo Co., Ltd. (Tokyo, Japan) and used as received. Pd(II) and $\mathrm{Pt}(\mathrm{IV})$ standard solutions were purchased from FUJIFILM Wako Pure Chemical Industries, Ltd. (Osaka, Japan) and used as received. Rh(III) standard solution was purchased from Kanto Chemical Co., Inc. (Tokyo, Japan) and used as received.

\subsection{Metal Precipitation Experiments from Metal-Containing Solutions}

To $\mathrm{HCl}$ solutions (1 mL) containing Pd(II), Pt(IV), and Rh(III) (1.0 mM each) were added aliphatic primary amine $(0.05 \mathrm{mmol})$ and the mixtures were shaken vigorously for $30 \mathrm{~min}$ at room temperature. After centrifugation $(7200 \times g, 10 \mathrm{~min})$, the metal concentration in the supernatant was determined by inductively coupled plasma atomic emission spectroscopy (ICP-AES, Hitachi High-Tech Science Corp., Tokyo, Japan). The used aliphatic primary amines and the $\mathrm{HCl}$ concentrations were changed in the metal precipitation experiments.

The metal precipitation experiments from single metal-containing solutions ( $\mathrm{Pd}(\mathrm{II}), \mathrm{Pt}(\mathrm{IV})$, or $\mathrm{Rh}(\mathrm{III}): 1.0 \mathrm{mM}, 6.0 \mathrm{M} \mathrm{HCl}$ ) using $n$-nonylamine were performed by the similar procedure described above. The amount of $n$-nonylamine and the shaking time were changed in the metal precipitation experiments.

\subsection{Mutual Separation of $P d(I I), P t(I V)$, and Rh(III)}

To a $4 \mathrm{~mL}$ of $1.0 \mathrm{M} \mathrm{HCl}$ solution containing Pd(II), Pt(IV), and $\mathrm{Rh}(\mathrm{III})$ (1.0 mM each) was added $n$-octylamine $(0.2 \mathrm{mmol})$ and the mixture was shaken vigorously for $30 \mathrm{~min}$ at room temperature. After 
centrifugation $(7200 \times g, 10 \mathrm{~min})$, the metal concentration in the supernatant was determined by ICP-AES. Then, an $11 \mathrm{M} \mathrm{HCl}$ solution was added to the supernatant to yield a $6.0 \mathrm{M} \mathrm{HCl}$ solution containing $\mathrm{Pd}(\mathrm{II})$ and $\mathrm{Rh}$ (III) (ca. $0.5 \mathrm{mM}$ each). To the resulting solution $(4 \mathrm{~mL})$ was added $n$-octylamine $(0.05 \mathrm{mmol})$ and the mixture was shaken vigorously for $30 \mathrm{~min}$ at room temperature. After centrifugation $(7200 \times g$, $10 \mathrm{~min}$ ), the metal concentration in the supernatant was determined by ICP-AES. Then, to the resulting supernatant $(2 \mathrm{~mL})$ was added $n$-decylamine $(0.1 \mathrm{mmol})$ and the mixture was shaken vigorously for $30 \mathrm{~min}$ at room temperature. After centrifugation $(7200 \times \mathrm{g}, 10 \mathrm{~min})$, the metal concentration in the supernatant was determined by ICP-AES.

\subsection{Isolation of Metal-Containing Precipitate}

To $10 \mathrm{~mL}$ of $6.0 \mathrm{M} \mathrm{HCl}$ solutions containing Pd(II), Pt(IV) or Rh(III) $(2.0 \mathrm{mM})$ were added n-nonylamine $(0.2 \mathrm{mmol}$, for $\mathrm{Pd}(\mathrm{II}))$ or $n$-octylamine $(0.2 \mathrm{mmol}$, for $\mathrm{Pt}(\mathrm{IV})$ and $\mathrm{Rh}(\mathrm{III}))$ and the mixtures were vigorously shaken for $30 \mathrm{~min}$ at room temperature. The resulting solid was collected by filtration and washed five times with a $6.0 \mathrm{M} \mathrm{HCl}$ solution. The solid was dried at room temperature for $48 \mathrm{~h}$ under vacuum. The $\mathrm{Rh}(\mathrm{III})$-containing precipitate using $n$-octylamine from a $2.0 \mathrm{M} \mathrm{HCl}$ solution was prepared in the similar manner.

\subsection{Measurements}

An ICP-AES instrument (SPS5510, Hitachi High-Tech Science Corp., Tokyo, Japan) was used for the metal concentration measurements. X-ray photoelectron spectroscopy (XPS) measurements were performed using an AXIS-ULTRA X-ray photoelectron spectrometer (Kratos Analytical Ltd., Manchester, UK). Element quantification was performed using the relative sensitivity factors supplied with the instrument control software (N 1 s: 0.477, Cl 2 s: 0.493, Pd 3d: 5.356, Pt 4d: 4.637, Rh 3d: 4.822). Thermogravimetric measurements were carried out using a STA7300 (Hitachi High-Tech Science Corp., Tokyo, Japan) at a heating rate of $10^{\circ} \mathrm{C} / \mathrm{min}$ under air flow $(200 \mathrm{~mL} / \mathrm{min})$.

\section{Results and Discussion}

\subsection{Metal Precipitation Experiments}

The metal recovery experiments from the mixture of $\mathrm{Pd}(\mathrm{II}), \mathrm{Pt}(\mathrm{IV})$, and $\mathrm{Rh}(\mathrm{III})$ in $\mathrm{HCl}$ were carried out using aliphatic primary amines as metal precipitants. The aliphatic primary amines used herein have linear-chain alkanes (from hexyl to dodecyl). The precipitation percentages of the metals were determined by ICP-AES analysis of the supernatants after centrifugation. Figure 1a-e shows the relationship between the precipitation of metals and $\mathrm{HCl}$ concentration. $n$-Hexylamine, which has the shortest alkyl chain in this study, did not work as a precipitant for Pd(II), Pt(IV), and Rh(III) regardless of the $\mathrm{HCl}$ concentrations (i.e., no precipitation); however, $n$-heptylamine and $n$-octylamine precipitated most of $\mathrm{Pt}(\mathrm{IV})$ (over $80 \%$ except for $n$-heptylamine in $1.0 \mathrm{M} \mathrm{HCl}$ ) in a wide range of $\mathrm{HCl}$ concentrations (1.0-8.0 M), whereas $\mathrm{Pd}(\mathrm{II})$ precipitation was below 5\%. Notably, $\mathrm{Rh}(\mathrm{III})$ precipitation occurred using the aliphatic amines except for $n$-hexylamine at $\mathrm{HCl}$ concentrations exceeding $1.0 \mathrm{M}$, and the precipitation percentages increased with the $\mathrm{HCl}$ concentrations, resulting in precipitation percentages exceeding $80 \%$ at high $\mathrm{HCl}$ concentrations $(>4 \mathrm{M} \mathrm{HCl})$. Thus, $n$-heptylamine and $n$-octylamine exclusively precipitated $\mathrm{Pt}(\mathrm{IV})$ in a $1.0 \mathrm{M} \mathrm{HCl}$ solution, while both $\mathrm{Pt}(\mathrm{IV})$ and $\mathrm{Rh}(\mathrm{III})$ were co-precipitated at higher $\mathrm{HCl}$ concentrations. The use of $n$-nonylamine, $n$-decylamine, and $n$-dodecylamine enabled the efficient precipitation of $\mathrm{Pd}(\mathrm{II})$ and $\mathrm{Pt}(\mathrm{IV})$ (over $80 \%$ ) in the studied $\mathrm{HCl}$ concentrations. Moreover, the precipitation of $\mathrm{Rh}(\mathrm{III})$ increased with the $\mathrm{HCl}$ concentrations and exceeded $90 \%$ at high $\mathrm{HCl}$ concentrations (> $4 \mathrm{M} \mathrm{HCl}$ ). Thus, $n$-nonylamine, $n$-decylamine, and $n$-dodecylamine can recover $\mathrm{Pd}(\mathrm{II}), \mathrm{Pt}(\mathrm{IV})$, and $\mathrm{Rh}(\mathrm{III})$ as precipitates in high yields at high $\mathrm{HCl}$ concentrations. These results evidently show that the $\mathrm{HCl}$ concentration did not particularly affect the precipitation behavior of $\mathrm{Pd}(\mathrm{II})$ and $\mathrm{Pt}(\mathrm{IV})$ irrespective of the used amine, whereas $\mathrm{Rh}$ (III) precipitation increased with the concentration of $\mathrm{HCl}$. Figure $2 \mathrm{a}, \mathrm{b}$ shows the effect of the alkyl chain length on 
metal precipitation in $1.0 \mathrm{M} \mathrm{HCl}$ and $6.0 \mathrm{M} \mathrm{HCl}$ solutions. The precipitation of $\mathrm{Pd}(\mathrm{II})$ required a longer alkyl length than octyl in both $1.0 \mathrm{M} \mathrm{HCl}$ and $6.0 \mathrm{M} \mathrm{HCl}$ solutions, while the $\mathrm{Pt}(\mathrm{IV})$ precipitation occurred using amines with alkyl chains longer than hexyl in both $1.0 \mathrm{M} \mathrm{HCl}$ and $6.0 \mathrm{M} \mathrm{HCl}$ solutions. The precipitation percentages of $\mathrm{Pt}(\mathrm{IV})$ increased in proportion to the length of the alkyl chain and reached approximately $100 \%$ at octyl in $1.0 \mathrm{M} \mathrm{HCl}$ solutions, while high $\mathrm{Pt}(\mathrm{IV})$ precipitation percentages over $80 \%$ were achieved using the alkyl amines longer than hexyl in $6.0 \mathrm{M} \mathrm{HCl}$ solutions. For the $\mathrm{Rh}(\mathrm{III})$ precipitation, the precipitation percentages gradually increased with the length of the alkyl chain and reached $50 \%$ by using $n$-dodecylamine in $1.0 \mathrm{M} \mathrm{HCl}$ solutions. The percentages of $\mathrm{Rh}$ (III) precipitation in $6.0 \mathrm{M} \mathrm{HCl}$ solutions exceeded $60 \%$ by using the alkyl amines longer than hexyl, although those in the $1.0 \mathrm{M} \mathrm{HCl}$ solutions were below $10 \%$ except for when $n$-dodecylamine was used. It is noteworthy that a near-quantitative recovery of $\mathrm{Rh}(\mathrm{III})$ as precipitates was achieved when the amines had long alkyl chains and the concentration of $\mathrm{HCl}$ was high. Furthermore, the metal-containing precipitates obtained in this study were easily collected by filtration.
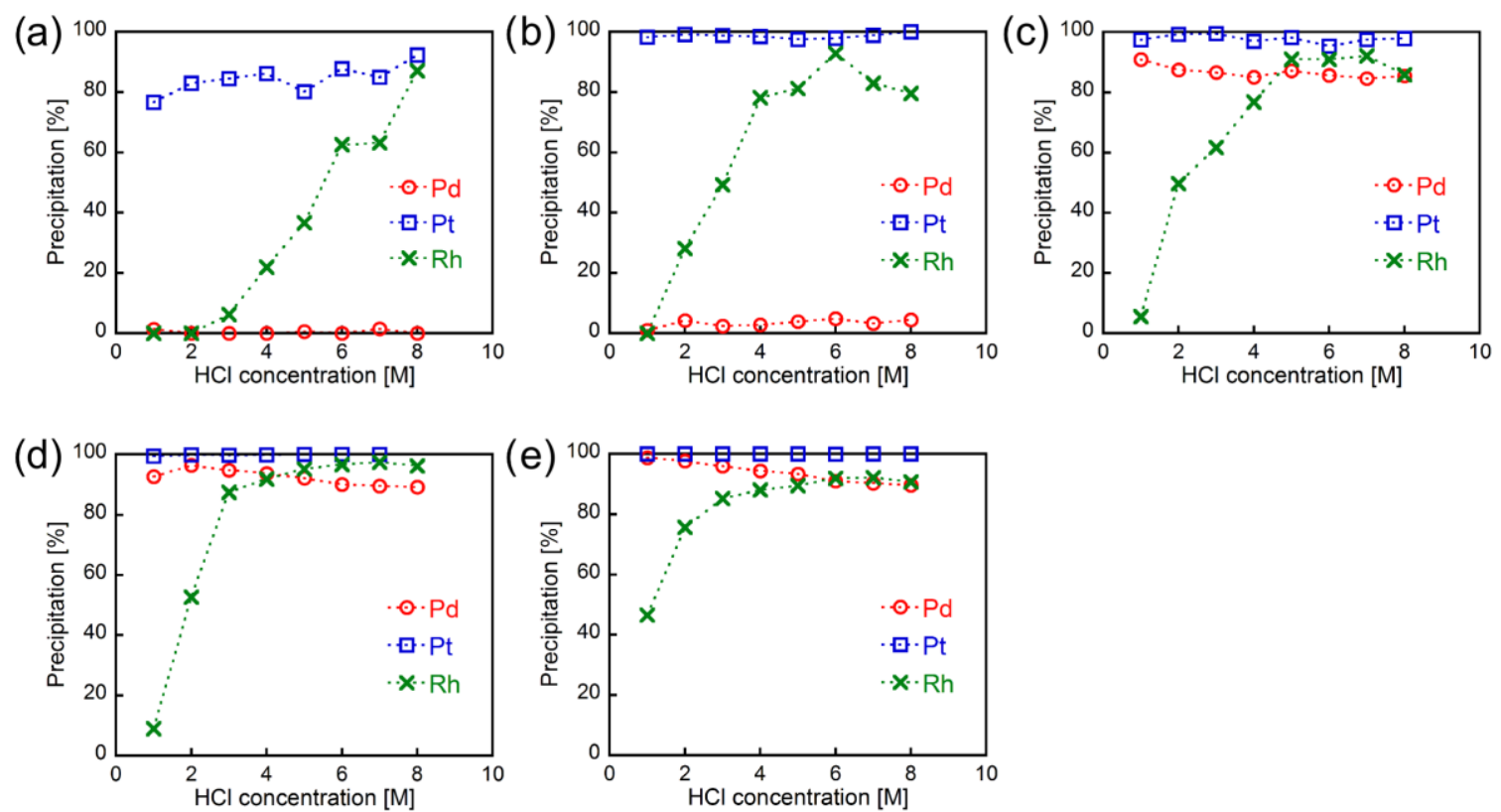

Figure 1. Metal precipitation from $\mathrm{HCl}$ solutions containing $\mathrm{Pd}(\mathrm{II}), \mathrm{Pt}(\mathrm{IV})$, and $\mathrm{Rh}$ (III) (each at $1 \mathrm{mM}$ ) using (a) $n$-heptylamine, (b) n-octylamine, (c) n-nonylamine, (d) $n$-decylamine, and (e) $n$-dodecylamine (amine: $50 \mathrm{mM}, 30 \mathrm{~min}$ of shaking).
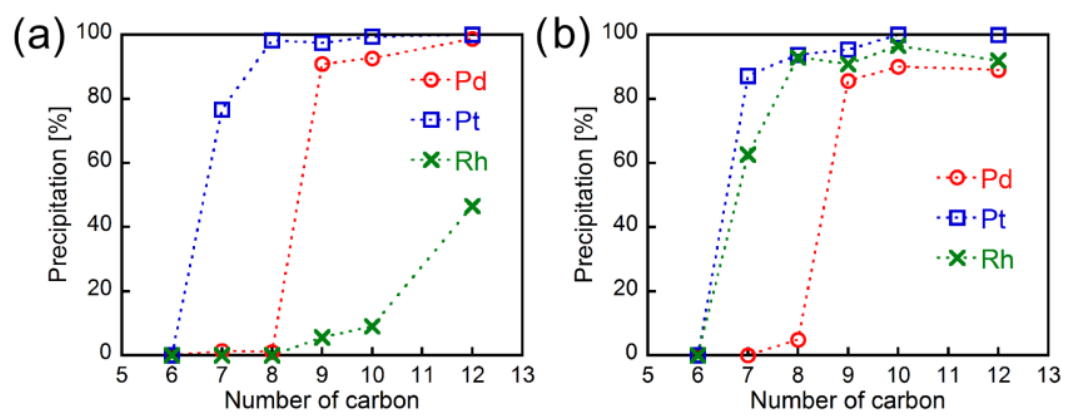

Figure 2. Relationship between metal precipitation and alkyl chain length of the amine in (a) $1.0 \mathrm{M}$ $\mathrm{HCl}$ solutions and (b) $6.0 \mathrm{M} \mathrm{HCl}$ solutions (metal: $1 \mathrm{mM}$ each, amine: $50 \mathrm{mM}, 30 \mathrm{~min}$ of shaking).

\subsection{Loading Amount and Shaking Time}

The dependence of the metal precipitation percentages on the loading amount of $n$-nonylamine was investigated using $6.0 \mathrm{M} \mathrm{HCl}$ solutions containing individual metals (Pd(II), $\mathrm{Pt}(\mathrm{IV})$, and $\mathrm{Rh}(\mathrm{III})$ ). 
We selected n-nonylamine as a typical example because it can precipitate all the three PGMs as shown in Figure 1c. The precipitation percentages of each metal increased with the loading amount of $n$-nonylamine and reached a plateau at [n-nonylamine]/[metal] $=10(\mathrm{~mol} / \mathrm{mol})$ when the single metal-containing solutions were used (Figure 3a). There was no significant difference in the precipitation behavior among the three metals.
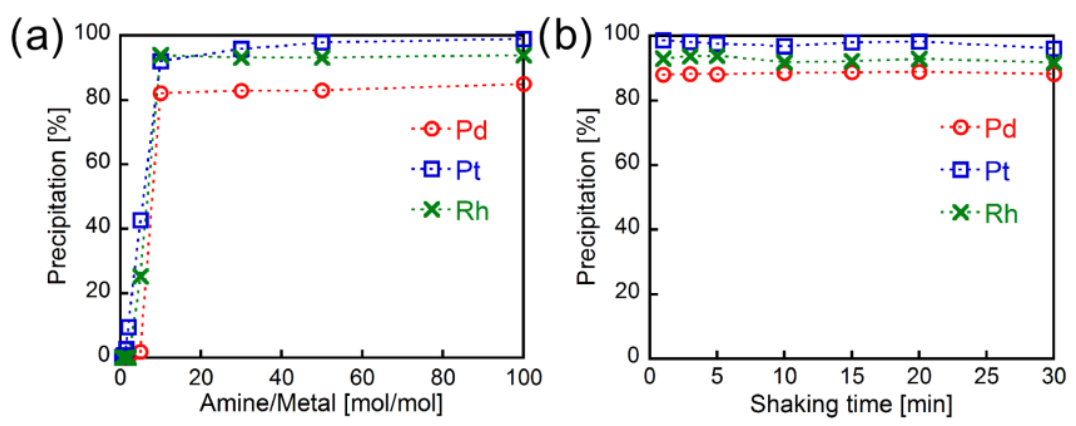

Figure 3. The effect of (a) $n$-nonylamine loading (30 min of shaking) and (b) shaking time on the metal precipitation (amine/metal $=50 \mathrm{~mol} / \mathrm{mol}$ ) from $6.0 \mathrm{M} \mathrm{HCl}$ solutions containing $1 \mathrm{mM}$ individual metals (Pd(II), Pt(IV), and Rh(III)).

The effect of the shaking time on metal precipitation was also examined in the condition of [n-nonylamine]/[metals] $=50(\mathrm{~mol} / \mathrm{mol})$ in $6.0 \mathrm{M} \mathrm{HCl}$ solutions containing individual metals $(\mathrm{Pd}(\mathrm{II})$, $\mathrm{Pt}(\mathrm{IV})$, and $\mathrm{Rh}(\mathrm{III}))$. Surprisingly, the precipitation percentages of the metals reached a maximum after shaking for $1 \mathrm{~min}$ (Figure $3 \mathrm{~b}$ ). This result clearly shows that PGM recovery by precipitation using aliphatic amines can be speedily completed.

\subsection{Mutual Separation of Pd(II), Pt(IV), and Rh(III)}

Based on the metal precipitation results relating to varying alkyl chain lengths and $\mathrm{HCl}$ concentrations, we performed a mutual separation of $\mathrm{Pd}(\mathrm{II}), \mathrm{Pt}(\mathrm{IV})$, and $\mathrm{Rh}$ (III) from a metal-mixed $\mathrm{HCl}$ solution. In the first precipitation step, $n$-octylamine was used as a precipitant because it can selectively precipitate $\mathrm{Pt}(\mathrm{IV})$ from $1.0 \mathrm{M} \mathrm{HCl}$ solutions (Figure $1 \mathrm{~b})$. As a result, $\mathrm{Pt}(\mathrm{IV})$ was recovered using n-octylamine from a $1.0 \mathrm{M} \mathrm{HCl}$ solution containing $\mathrm{Pd}(\mathrm{II}), \mathrm{Pt}(\mathrm{IV})$, and $\mathrm{Rh}(\mathrm{III})(1 \mathrm{mM}$ each). Then, the $\mathrm{HCl}$ concentration of the resulting solution $(\mathrm{Pd}, \mathrm{Rh}: 1 \mathrm{mM}$ each, $1.0 \mathrm{M} \mathrm{HCl})$ increased by adding an $11 \mathrm{M} \mathrm{HCl}$ solution and the $6.0 \mathrm{M} \mathrm{HCl}$ solution (Pd, Rh: $0.5 \mathrm{mM}$ each) was obtained. In the second precipitation step, $n$-octylamine was added to the metal-containing $6.0 \mathrm{M} \mathrm{HCl}$ solution, and $\mathrm{Rh}(\mathrm{III})$ was recovered by precipitation. In the third precipitation step, the remaining Pd(II) was recovered using $n$-decylamine as a precipitant. As shown in Figure 4, each target metal is recovered as a precipitate over $75 \%$, and co-precipitation of other metals is suppressed below $10 \%$. Generally, $\mathrm{Pt}(\mathrm{IV})$ recovery in preference to $\mathrm{Pd}(\mathrm{II})$ is difficult according to the order of the PGM extractability $[15,16]$. Furthermore, $\mathrm{Rh}(\mathrm{III})$ in $\mathrm{HCl}$ cannot be extracted in preference to $\mathrm{Pd}(\mathrm{II})$ and $\mathrm{Pt}(\mathrm{IV})$ using conventional solvent extraction methods [14-16]. However, we achieved a mutual separation of $\mathrm{Pt}(\mathrm{IV}), \mathrm{Rh}(\mathrm{III})$, and $\mathrm{Pd}(\mathrm{II})$ in this order using aliphatic primary amines by changing the $\mathrm{HCl}$ concentration and alkyl chain length.

\subsection{XPS Analysis of Metal-Containing Precipitates}

XPS measurements of the metal-containing precipitates were carried out to analyze elemental composition. The precipitates were prepared by adding $n$-nonylamine (for $\mathrm{Pd}(\mathrm{II})$ ) or $n$-octylamine (for Pt(IV) and $\mathrm{Rh}(\mathrm{III})$ ) to the $6.0 \mathrm{M} \mathrm{HCl}$ solutions containing individual metals (Pd(II), Pt(IV), and $\mathrm{Rh}(\mathrm{III})$ ). Prior to the measurements, the precipitates were washed with $\mathrm{HCl}$ to remove excess amine. The characteristic XPS peaks assigned to the Pd 3d, Pt 4d, and Rh 3d were observed for the Pd-, Pt-, and Rh-containing precipitates, respectively (Figure 5a-c). Furthermore, the peaks attributed 
to the $\mathrm{N} 1 \mathrm{~s}, \mathrm{C} 1 \mathrm{~s}, \mathrm{Cl} 2 \mathrm{~s}$, and $\mathrm{Cl} 2 \mathrm{p}$ were also observed for all the three samples. The N:Cl:metal atomic ratios were calculated from the photoelectron peak areas using the atomic sensitivity factors. The atomic ratios (N:Cl:metal) were calculated to be 2.0:3.9:1.0 (Pd-containing precipitate), 2.0:6.1:1.0 (Pt-containing precipitate), and 6.0:9.1:1.0 (Rh-containing precipitate) (Figure 5a-c). Pd(II) and Pt(IV) exist as chloro-complex anions, $\left[\mathrm{PdCl}_{4}\right]^{2-}$ and $\left[\mathrm{PtCl}_{6}\right]^{2-}$, in $\mathrm{HCl}$ solutions [14]. Since the aliphatic amines used herein form ammonium cations in $\mathrm{HCl}$, the metal-containing precipitates will be the ion-pairs composed of metal chloro-complex anions and ammonium cations. The atomic ratios calculated from the XPS data are consistent with the expected composition of the Pd- and Pt-containing precipitates, as shown in Figure $6 a, b$. For $\mathrm{Rh}(\mathrm{III})$, the predominant species of $\mathrm{Rh}$ in $6.0 \mathrm{M} \mathrm{HCl}$ is $\left[\mathrm{RhCl}_{6}\right]^{3-}$ [21]. Recently, we reported that aromatic primary amines selectively form $\mathrm{Rh}$-containing precipitates comprising anilinium cation/chloride anion/[ $\left.\mathrm{RhCl}_{6}\right]^{3-}$ at a $6: 3: 1$ ratio $(\mathrm{N}: \mathrm{Cl}: \mathrm{Rh}=6: 9: 1)[18]$. The XPS result indicates that aliphatic primary amines also form unique ion-pair complexes composed of ammonium cation/chloride anion/[ $\left.\mathrm{RhCl}_{6}\right]^{3-}$ in a 6:3:1 ratio (Figure $6 \mathrm{c}$ ).

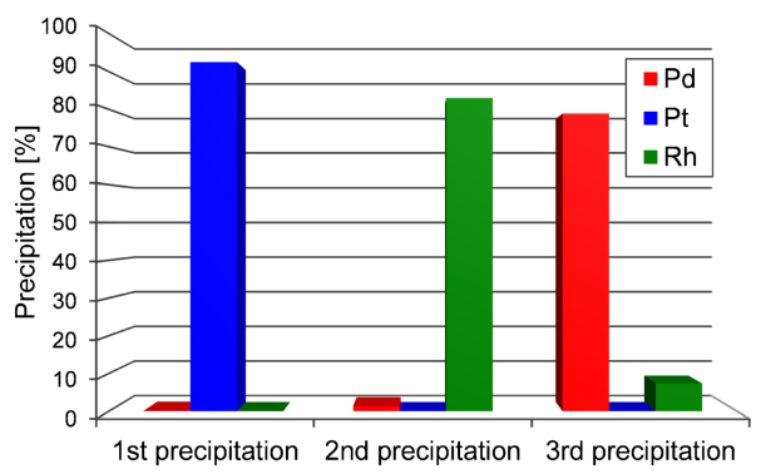

Figure 4. Mutual separation of $\mathrm{Pd}(\mathrm{II}), \mathrm{Pt}(\mathrm{IV})$, and $\mathrm{Rh}(\mathrm{III})$ from a $1.0 \mathrm{M} \mathrm{HCl}$ solution containing $\mathrm{Pd}(\mathrm{II})$, $\mathrm{Pt}(\mathrm{IV})$, and $\mathrm{Rh}(\mathrm{III})$ (1 $\mathrm{mM}$ each).

(a)

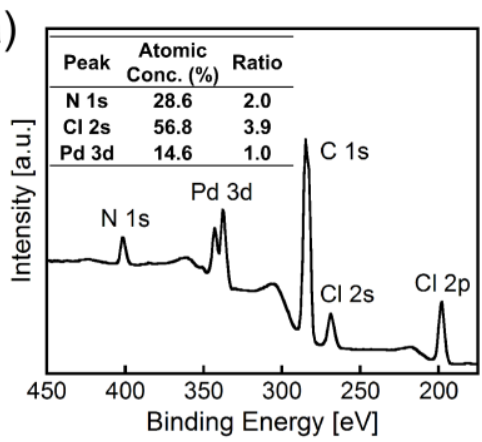

(c)

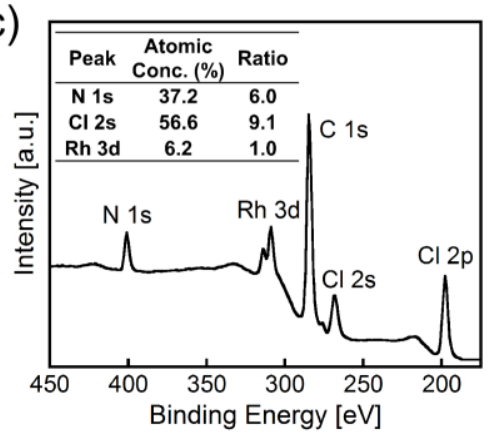

(b)

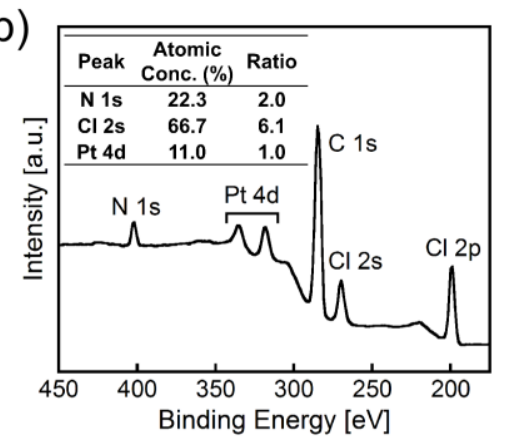

(d)

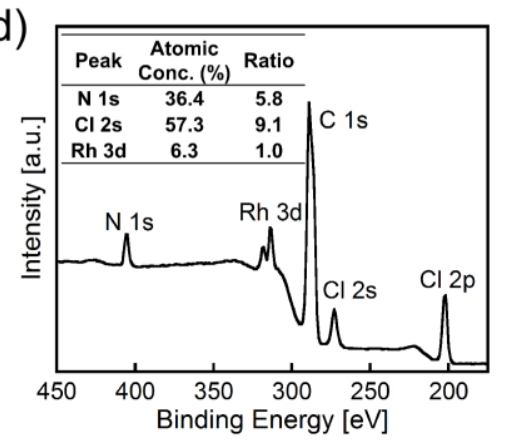

Figure 5. XPS spectra of the precipitates of (a) $\mathrm{Pd}(\mathrm{II})$ with $n$-nonylamine, (b) $\mathrm{Pt}(\mathrm{IV})$ with $n$-octylamine, and (c) $\mathrm{Rh}$ (III) with $n$-octylamine prepared from $6.0 \mathrm{M} \mathrm{HCl}$ solutions, and (d) the precipitate of $\mathrm{Rh}$ (III) with $n$-octylamine prepared from a $2.0 \mathrm{M} \mathrm{HCl}$ solution. 
(a)

(b)

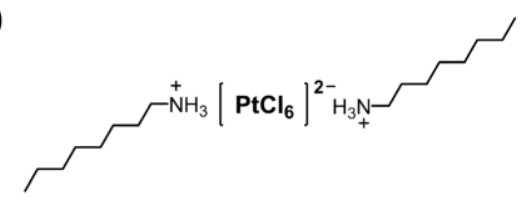

(c)

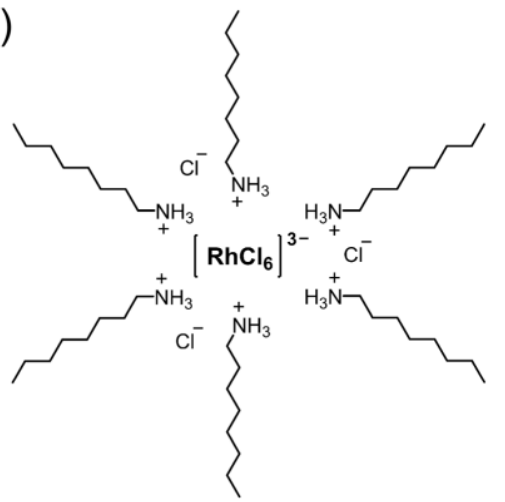

Figure 6. Expected chemical structures of the ion-pair complexes of (a) $\operatorname{Pd}(\mathrm{II})$ with $n$-nonylamine, (b) $\mathrm{Pt}(\mathrm{IV})$ with $n$-octylamine, and (c) Rh(III) with $n$-octylamine.

\subsection{Thermogravimetric Analysis of Metal-Containing Precipitates}

The ratios of metals and aliphatic primary amines in the metal-containing precipitates were also examined by thermogravimetric analysis (TGA). The precipitates used for the evaluation were prepared using n-nonylamine (for $\mathrm{Pd}(\mathrm{II})$ ) or $n$-octylamine (for $\mathrm{Pt}(\mathrm{IV})$ and $\mathrm{Rh}(\mathrm{III})$ ) and individual metal-containing $6.0 \mathrm{M} \mathrm{HCl}$ solutions. The weight loss observed in the range of $200-500{ }^{\circ} \mathrm{C}$ for all the three samples is attributed to the decomposition and volatilization of amines and chlorine (Figure $7 \mathrm{a}-\mathrm{C}$ ). The residual weights of $\mathrm{Pd}-, \mathrm{Pt}-$, and Rh-containing precipitates after heating at $750{ }^{\circ} \mathrm{C}$ were found to be 22.5\%, 28.7\%, and 10.3\%, respectively. $\mathrm{PdCl}_{2}, \mathrm{PtCl}_{4}$, and $\mathrm{RhCl}_{3}$ form $\mathrm{Pd}$ oxide (PdO), zerovalent $\mathrm{Pt}$, and $\mathrm{Rh}$ oxide $\left(\mathrm{Rh}_{2} \mathrm{O}_{3}\right)$ after combustion below $800{ }^{\circ} \mathrm{C}$, respectively [22]. The expected weight fractions after the combustion of ion-pair complexes shown in Figure $6 a-c$ are consistent with the experimental results of the TGA, as summarized in Table 1. The TGA results strongly support that the metal-containing precipitates consist of the ion-pairs depicted in Figure 6a-c.
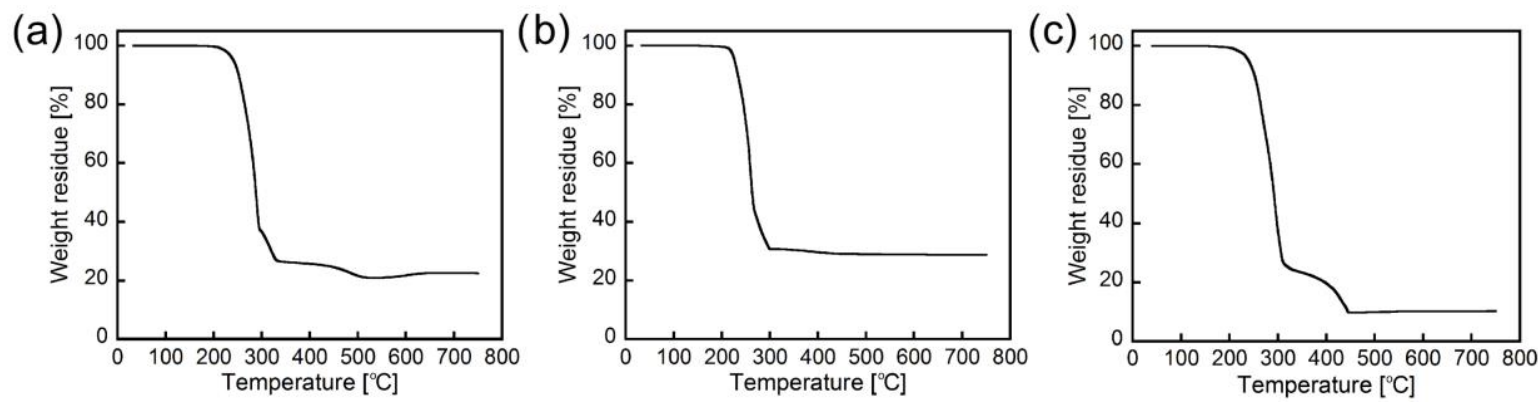

Figure 7. TG curves of the precipitates of (a) $\mathrm{Pd}(\mathrm{II})$ with $n$-nonylamine, (b) $\mathrm{Pt}(\mathrm{IV})$ with $n$-octylamine, and (c) $\mathrm{Rh}(\mathrm{III})$ with $n$-octylamine at a heating rate of $10^{\circ} \mathrm{C} / \mathrm{min}$ under air flow $(200 \mathrm{~mL} / \mathrm{min})$.

Table 1. Weight fractions after the combustion of the precipitates.

\begin{tabular}{ccc}
\hline Metal & Ash at $\mathbf{7 5 0}{ }^{\circ} \mathbf{C}^{\mathbf{a}}$ & Expected Weight Fraction $^{\mathbf{b}}$ \\
\hline $\mathrm{Pd}(\mathrm{II})$ & $22.8 \%$ & $22.5 \%$ \\
$\mathrm{Pt}(\mathrm{IV})$ & $28.7 \%$ & $29.2 \%$ \\
$\mathrm{Rh}(\mathrm{III})$ & $10.3 \%$ & $10.5 \%$
\end{tabular}

${ }^{a}$ Weight fractions of ash after TGA shown in Figure 7. ${ }^{b}$ Expected weight fractions after combustion of ion-pair complexes shown in Figure 6.

\subsection{Metal Precipitation Behavior}

Figure 2a,b show that the metal precipitation of Pd(II) highly depends on the alkyl chain length of the amines. Since all the amines used herein are primary and have linear alkane chains, there is 
no difference in the properties of their amine groups, such as electron density and proton affinity. Therefore, the difference among the amines is only their hydrophobicity, i.e., their solubility in $\mathrm{HCl}$. It is assumed that the hydrophobicity of the short alkyl amines (hexyl, heptyl, and octyl) is insufficient to precipitate the ion-pair composed of one Pd chloro-complex anion $\left(\left[\mathrm{PdCl}_{4}\right]^{2-}\right)$ and two ammonium cations, whereas $\mathrm{Pt}(\mathrm{IV})$ can be recovered as precipitates using the alkyl amines longer than hexyl. To investigate the difference in the solubility of the metal-containing precipitates, the saturating concentrations were measured for the ion-pairs composed of $\left[\mathrm{PdCl}_{4}\right]^{2-}$ or $\left[\mathrm{PtCl}_{6}\right]^{2-}$ and $n$-octylammonium cations. The ion-pairs were prepared by evaporating the $1: 2(\mathrm{~mol} / \mathrm{mol}) \mathrm{mixed}$ solution of the metal chloro-complex anions and $n$-octylamine in $1.0 \mathrm{M} \mathrm{HCl}$ solutions. The saturating concentrations of the $\mathrm{Pd}$ - and Pt-containing ion-pairs in $6.0 \mathrm{M} \mathrm{HCl}$ were 5.6 and 0.94 , respectively. This result clearly shows that the hydrophilicity of the Pd-containing ion-pairs is higher than that of the Pt-containing ones. Consequently, the amines with alkyl chains longer than octyl are necessary to form $\mathrm{Pd}$-containing precipitates. The difference in the solubility of the Pd-and Pt-containing ion-pairs is derivable from the difference in the number of $\mathrm{Cl}$ : the Pd-containing ion-pair possessing only four $\mathrm{Cl}$ would be less hydrophobic than the Pt-containing one with six $\mathrm{Cl}$.

The precipitation percentages of $\mathrm{Rh}(\mathrm{III})$ increase with the $\mathrm{HCl}$ concentrations, although those of $\mathrm{Pd}(\mathrm{II})$ and $\mathrm{Pt}(\mathrm{IV})$ are quite independent of the $\mathrm{HCl}$ concentrations. $\mathrm{Rh}(\mathrm{III})$ forms several anion species in $\mathrm{HCl}$, such as $\left[\mathrm{RhCl}_{4}\left(\mathrm{H}_{2} \mathrm{O}\right)_{2}\right]^{-},\left[\mathrm{RhCl}_{5}\left(\mathrm{H}_{2} \mathrm{O}\right)\right]^{2-}$, and $\left[\mathrm{RhCl}_{6}\right]^{3-}$, and the abundance ratio of $\left[\mathrm{RhCl}_{6}\right]^{3-}$ increases with $\mathrm{HCl}$ concentrations $[18,20,21]$. For example, $\left[\mathrm{RhCl}_{6}\right]^{3-}$ dominantly exists in $6.0 \mathrm{M}$ $\mathrm{HCl}\left(\left[\mathrm{RhCl}_{6}\right]^{3-}: 91 \%\right)[18,20]$. From the results of the XPS and TGA of the Rh-containing precipitate using a $6.0 \mathrm{M} \mathrm{HCl}$ solution, $\left[\mathrm{RhCl}_{6}\right]^{3-}$ is precipitated to form an ion-pair complex shown in Figure $6 \mathrm{c}$. Therefore, we assumed that the preferential precipitation of $\left[\mathrm{RhCl}_{6}\right]^{3-}$ occurred independently of the $\mathrm{HCl}$ concentrations by the ion-pair formation. To examine the precipitated Rh species, the XPS measurement was carried out for the precipitate formed by adding $n$-octylamine to a Rh-containing 2.0 $\mathrm{M} \mathrm{HCl}$ solution. From the XPS spectrum of the precipitate composed of $n$-octylamine and $\mathrm{Rh}$, the atomic ratio of $\mathrm{N}: \mathrm{Cl}: \mathrm{Rh}$ was calculated to be 5.8:9.1:1.0, indicating that the Rh-containing precipitate prepared from a $2.0 \mathrm{M} \mathrm{HCl}$ solution had the same composition as that from a $6.0 \mathrm{M} \mathrm{HCl}$ solution (Figure $5 \mathrm{~d}$ ). Since the distribution of the Rh species in $2.0 \mathrm{M} \mathrm{HCl}$ is reported to be $78 \%$ of $\left[\mathrm{RhCl}_{5}\left(\mathrm{H}_{2} \mathrm{O}\right)\right]^{2-}$ and $8 \%$ of $\left[\mathrm{RhCl}_{6}\right]^{3-}[18,20]$, the XPS result evidently shows the selective precipitation of $\left[\mathrm{RhCl}_{6}\right]^{3-}$ in $2.0 \mathrm{M} \mathrm{HCl}$ using $n$-octylamine. The precipitation percentage of $\mathrm{Rh}$ (III) in $2.0 \mathrm{M} \mathrm{HCl}$ using $n$-octylamine (28\%) was higher than the abundance ratio of $\left[\mathrm{RhCl}_{6}\right]^{3-}(8 \%)$, which would be consequent of an equilibrium shift from $\left[\mathrm{RhCl}_{4}\left(\mathrm{H}_{2} \mathrm{O}\right)_{2}\right]^{-}$and $\left[\mathrm{RhCl}_{5}\left(\mathrm{H}_{2} \mathrm{O}\right)\right]^{2-}$ to $\left[\mathrm{RhCl}_{6}\right]^{3-}$. The precipitation behavior of $\mathrm{Rh}(\mathrm{III})$ using aliphatic primary amines is similar to that using 4-alkylanilines [18]. On the other hand, only aliphatic primary amines can precipitate $\mathrm{Pd}(\mathrm{II})$ and $\mathrm{Pt}(\mathrm{IV})$ even at high $\mathrm{HCl}$ concentrations: 4-alkylanilines do not form $\mathrm{Pd}(\mathrm{II})$ - and $\mathrm{Pt}(\mathrm{IV})$-containing precipitates at high $\mathrm{HCl}$ concentrations $(>5 \mathrm{M} \mathrm{HCl})$. Although 4-alkylanilines are advantageous from the viewpoint of $\mathrm{Rh}(\mathrm{III})$-selective precipitation, aliphatic primary amines have the advantages of the capability in the mutual separation of $\mathrm{Pd}(\mathrm{II}), \mathrm{Pt}(\mathrm{IV})$, and $\mathrm{Rh}(\mathrm{III})$ as well as in the recovery by precipitation of $\mathrm{Pd}(\mathrm{II})$ and $\mathrm{Pt}(\mathrm{IV})$ at high $\mathrm{HCl}$ concentrations.

\section{Conclusions}

The recovery of $\mathrm{Pd}(\mathrm{II}), \mathrm{Pt}(\mathrm{IV})$, and $\mathrm{Rh}(\mathrm{III})$ by precipitation was achieved using aliphatic primary amines with linear-chain alkanes as precipitants. Pt(IV) was precipitated using the amines with alkyl chains longer than hexyl independent of $\mathrm{HCl}$ concentration, while the precipitation of $\mathrm{Pd}(\mathrm{II})$ required the longer alkyl amines than octyl, regardless of the $\mathrm{HCl}$ concentration. However, $\mathrm{Rh}$ (III) was recovered by precipitation at high $\mathrm{HCl}$ concentrations using amines longer than hexyl. The mutual separation of $\mathrm{Pt}(\mathrm{IV}), \mathrm{Rh}(\mathrm{III})$, and $\mathrm{Pd}(\mathrm{II})$, in this order, was successfully achieved by changing the $\mathrm{HCl}$ concentrations and alkyl chain lengths of the amines. XPS and TGA results clearly showed that the metal-containing precipitates are ion-pair complexes composed of metal chloro-complex anions and ammonium cations. It is noteworthy that $\mathrm{Rh}(\mathrm{III})$ formed a unique ion-pair complex comprising ammonium cations of 
aliphatic amines/chloride anions/[RhCl 6$]^{3-}=6: 9: 1$. This PGM precipitation method, using aliphatic primary amines, is a promising application in the PGM recycling.

Author Contributions: Y.S., S.Y., and Y.H. performed the experiments and contributed the data analysis. M.J. participated in the discussion on the results and the preparation of the paper. K.M. designed the research, analyzed the data, and wrote the paper. All authors have read and agreed to the published version of the manuscript.

Funding: This work was supported by the Japan Society for the Promotion of Science (JSPS) KAKENHI (Grant-in-Aid for Young Scientists (B) 17K12835), the Environment Research and Technology Development Fund (3RF-1902) of the Environmental Restoration and Conservation Agency of Japan, and Akita University Support for Fostering Research Project.

Conflicts of Interest: The authors declare no conflict of interest.

\section{References}

1. Alonso, E.; Field, F.R.; Kirchain, R.E. Platinum availability for future automotive technologies. Environ. Sci. Technol. 2012, 46, 12986-12993. [CrossRef] [PubMed]

2. Khaliq, A.; Rhamdhani, M.A.; Brooks, G.; Masood, S. Metal extraction processes for electronic waste and existing industrial routes: A review and Australian perspective. Resources 2014, 3, 152-179. [CrossRef]

3. Froehlich, P.; Lorenz, T.; Martin, G.; Brett, B.; Bertau, M. Valuable metals-recovery processes, current trends, and recycling strategies. Angew. Chem. Int. Ed. 2017, 56, 2544-2580. [CrossRef] [PubMed]

4. Kašpar, J.; Fornasiero, P.; Hickey, N. Automotive catalytic converters: Current status and some perspectives. Catal. Today 2003, 77, 419-449. [CrossRef]

5. Hagelüken, C. Recycling the platinum group metals: A European perspective. Platinum Met. Rev. 2012, 56, 29-35. [CrossRef]

6. Sun, P.P.; Lee, J.Y.; Lee, M.S. Separation of Pt (IV) and Rh (III) from chloride solution by solvent extraction with amine and neutral extractants. Mater. Trans. 2011, 52, 2071-2076. [CrossRef]

7. Cieszynska, A.; Wieczorek, D. Extraction and separation of palladium (II), platinum (IV), gold (III) and rhodium (III) using piperidine-based extractants. Hydrometallurgy 2018, 175, 359-366. [CrossRef]

8. Gupta, B.; Singh, I. Extraction and separation of platinum, palladium and rhodium using Cyanex 923 and their recovery form real samples. Hydrometallurgy 2013, 134-135, 11-18. [CrossRef]

9. Truong, H.T.; Lee, M.S.; Senanayake, G. Separation of Pt (IV), Rh (III) and Fe (III) in acid chloride leach solutions of glass scraps by solvent extraction with various extractants. Hydrometallurgy 2018, 175, 232-239. [CrossRef]

10. Firmansyah, M.L.; Kubota, F.; Goto, M. Solvent extraction of Pt (IV), Pd (II), and Rh (III) with the ionic liquid trioctyl(dodecyl) phosphonium chloride. J. Chem. Technol. Biotechnol. 2018, 93, 1714-1721. [CrossRef]

11. Rzelewska-Piekut, M.; Regel-Rosocka, M. Separation of Pt (IV), Pd (II), Ru (III) and Rh (III) from model chloride solutions by liquid-liquid extraction with phosphonium ionic liquids. Sep. Purif. Technol. 2019, 212, 791-801. [CrossRef]

12. Narita, H.; Tanaka, M.; Morisaku, K. Palladium extraction with $N, N, N^{\prime}, N^{\prime}$-tetra- $n$-octyl-thiodiglycolamide. Miner. Eng. 2008, 21, 483-488. [CrossRef]

13. Ortet, O.; Paiva, A.P. Development of tertiary thioamide derivatives to recover palladium (II) from simulated complex chloride solutions. Hydrometallurgy 2015, 151, 33-41. [CrossRef]

14. Bernardis, F.L.; Grant, R.A.; Sherrington, D.C. A review of methods of separation of the platinum-group metals through their chloro-complexes. React. Funct. Polym. 2005, 65, 205-217. [CrossRef]

15. Rydberg, J.; Cox, M.; Musikas, C.; Choppin, G.R. Solvent Extraction Principles and Practice, 2nd ed.; Marcel Dekker, Inc.: New York, NY, USA, 2004.

16. Nikoloski, A.N.; Ang, K.L. Review of the application of ion exchange resins for the recovery of platinum-group metals from hydrochloric acid solutions. Miner. Process. Extract. Metall. Rev. 2014, 35, 369-389. [CrossRef]

17. Matsumoto, K.; Yamakawa, S.; Jikei, M. Selective recovery of platinum (IV) from palladium (II)-containing solution using 4-(hexyloxy)aniline. Chem. Lett. 2017, 46, 22-24. [CrossRef]

18. Matsumoto, K.; Yamakawa, S.; Sezaki, Y.; Katagiri, H.; Jikei, M. Preferential precipitation and selective separation of $\mathrm{Rh}(\mathrm{III})$ from $\mathrm{Pd}(\mathrm{II})$ and $\mathrm{Pt}(\mathrm{IV})$ using 4-alkylanilines as precipitants. ACS Omega 2019, 4, 1868-1873. [CrossRef] 
19. Matsumoto, K.; Hata, Y.; Sezaki, Y.; Katagiri, H.; Jikei, M. Highly selective Rh(III) recovery from $\mathrm{HCl}$ solutions using aromatic primary diamines via formation of three-dimensional ionic crystals. ACS Omega 2019, 4, 14613-14620. [CrossRef]

20. Matsumoto, K.; Yamakawa, S.; Haga, K.; Ishibashi, K.; Jikei, M.; Shibayama, A. Selective and preferential separation of rhodium (III) from palladium (II) and platinum (IV) using a $m$-phenylene diamine-containing precipitant. Sci. Rep. 2019, 9, 12414. [CrossRef]

21. Benguerel, E.; Demopoulos, G.P.; Harris, G.B. Speciation and separation of rhodium (III) from chloride solutions: A critical review. Hydrometallurgy 1996, 40, 135-152. [CrossRef]

22. Jóźwiak, W.K.; Maniecki, T.P. Influence of atmosphere kind on temperature programmed decomposition of noble metal chlorides. Thermochim. Acta 2005, 435, 151-161. [CrossRef]

(C) 2020 by the authors. Licensee MDPI, Basel, Switzerland. This article is an open access article distributed under the terms and conditions of the Creative Commons Attribution (CC BY) license (http://creativecommons.org/licenses/by/4.0/). 